\title{
The Elias Project: Using the Near-Death Experience Potential in Therapy
}

\author{
Dr. phil. Engelbert Winkler \\ Klinischer U. Gesundheitspsychologe \\ Psychotherapeut, Wörgl, Austria
}

This essay describes the therapeutic usefulness of near-death experiences (NDEs). The fundamental hypothesis is that reports of NDEs together with relevant research can be understood to be a modern book of death and dying, one that is not only useful but also applicable to therapeutic purposes.

I describe an actual case of a suicidal boy who was successfully treated through the use of NDEs. This event developed into what came to be called the Elias Project. The foundation of the Elias Project is in the form of two texts with commentary, one for adults and one for children. Both texts have been distilled out of a large number of NDE reports. Also included are clinical cases that have to do with difficult and varied psychological problems. These have been included in the Occidental Book of Death and Dying because this approach has proved its therapeutic effectiveness.

\section{The Elias Project: Using the NDE Potential in Therapy}

\section{Patrick-A Child Who Decided to Die}

Some years ago the department of social services referred to me a new client: a suicidal 9-year-old boy. I had no idea what a challenge

Dr. Engelbert J. Winkler is a psychotherapist and clinical psychologist in Austria. Reprint requests should be addressed to Dr. Winkler at the Klinischer U. Gesundheitspsychologe Psychotherapeut, Gerichtl. Beid. Sachverständiger, A-6300 Wörgl, JohannSeisl-Str. 7, Austria. 
this would be. Some months previously Patrick's father had hung himself. Since that time Patrick had developed various behavioral problems, some of which were very serious, including the idea to kill himself. With increasing frequency he communicated his intention to end his life. This brought his mother and a number of professional (and many nonprofessional) helpers to the edge of desperation. Following my examination of Patrick, I saw that his threats of suicide must be taken seriously. First of all, I arranged for long-term family therapy that included all family members. To this I added a component of crisis intervention that involved working with the theme of death and dying in a way appropriate to Patrick's age. This proved to be extraordinarily difficult because Patrick showed no willingness to participate in the usual child-oriented therapeutic approaches. He withdrew more and more into himself, was noticeably more troubled and commented that he would not live to see his next birthday, which was six months away. A variety of individual and family approaches were attempted but failed to reach Patrick in his hopelessness. Then I recalled the interesting effect that the visions of those who have had a near-death experience can have on suicidal people.

I had previously been involved in a project to investigate what effect was left with people who had passed through a near-death experience, and in the context of this research I learned about the paradoxical effect of NDEs on people who had attempted suicide. On the one hand, the content of the NDE is for most people positive-so positive, in fact, that most of them only unwillingly return to this life. On the other hand, most of these people also discover a new joy in living that lasts years afterwards. In my research I had met both men and women who had attempted suicide, but their attempts had taken them only to the edge of death. There they found a "beauty beyond any earthly ability to imagine," as one person put it, and yet they had no thought to repeat their suicide attempt. On the contrary, the deeper the NDE was, the more all self-destructive impulses were dissolved. Beyond this, the reason that had led the person to attempt suicide was often no longer present following his or her near-death vision. It was not unusual that feelings of the meaninglessness of life and self-worthlessness were transformed into a sense of the richness of life and all its possibilities.

Thus I knew the positive effects of an NDE on adults. But how might this affect a child? I had no idea how a 9-year-old boy who had decided to follow his dead father would react to the powerful images that are common in NDEs. Might they strengthen his wish to die? On the other hand, I (and others) had done all we could think of to do. Consulting 
with other experienced colleagues gave me no new therapeutic insights for working with Patrick, and as his mental condition became more serious, I decided on an experiment with some risk.

I organized the typical experiences of those who had had a neardeath vision into a text that was appropriate for the mental development and understanding of a child. Then I gave it to a wellknown art master who worked with the children of a local junior high school. The children were asked to paint pictures to go with the story. The results were astounding. The pictures they created gave me the impression that they still had some memories of that place to which we all must return some day. Their pictures contained details that went beyond what I had included in the story.

This story, which I called "The Day Elias Died," was my last hope for Patrick. Under special circumstances the pictures and story was shown to Patrick, his siblings, and mother. The entire family was spontaneously changed. Patrick showed a deep interest in the text and pictures and, along with the other family members, became deeply involved in it. The children painted pictures for themselves of their favorite parts of the story and-for the first time-talked about the death of their father with their mother. Patrick's suicidal thoughts started fading away and at last disappeared. At the same time his social behaviour changed dramatically: his previous very aggressive tendencies, particularly toward his siblings, dissolved into expressions of reconciliation. Patrick's "return" to the family group obviated his self-destructive impulse and he was soon excitedly looking forward to his birthday. The decisive change was the newly won ability of the family to speak without fear about the death of the father and further, necessary, family therapy could continue in a more relaxed atmosphere.

\section{Toward a Contemporary Book of Death and Dying}

This story, "The Day Elias Died," later proved useful in other difficult cases. It gradually became clear to me that here was a highly useful healing tool. Increasingly I began to incorporate elements of the NDE in my therapeutic work not only with children but also with adults. The results were often more successful than if I had used more conventional methods. I offer two examples here: One was a mother terminally ill with cancer who could not give herself permission to die and the other was a member of a fundamentalist religious group who was terrified of what he believed was to come after death. In both 
cases, the positive effects supported further applications of this unconventional method. I have continued to expand the area in which I make use of this approach and I feel I have not yet reached the healing boundaries, to say nothing of going too far. The Elias Project took on unforeseeable dimensions.

Using accounts of the contents of NDEs in various areas of healing work has proved to be effective again and again. Thus it is not too extreme to consider a new kind of a Book of Death and Dying that would be a collection of the various oral and written accounts of the NDE which are to be found within our $21^{\text {st }}$ century high tech culture. In this way therapeutic work instrumenting NDEs would then merely be representing the contemporary tradition of death and dying, of course, in a positive healing way.

Today I see the Elias Project as an attempt to develop a comprehensive approach to the use of an occidental death and dying tradition in the areas of therapy, counseling, and personal growth. The essential elements of the project are the two texts I have written: one for adults and one for children. No matter how one is personally disposed in regard to NDEs, nevertheless, their unusual usefulness has been proven beyond doubt. Therefore it is reasonable to speak of a Book of Death and Dying as a medicine or a truly healing tool. Using special strategies like hypnosis, breathwork, and lucid dreaming can increase their effectiveness.

\section{Reference}

Winkler, E. (1996). Das Abendländische Totenbuch [The occidental book of death and dying]. Hamburg, Germany: Corona. 